\title{
Changes in airway function and bronchial responsiveness after acute occupational exposure to chlorine leading to treatment in a first aid unit
}

\author{
Christophe Leroyer, Jean-Luc Malo, Claire Infante-Rivard, Jean-Guy Dufour, \\ Denyse Gautrin
}

\begin{abstract}
Objectives-To describe the baseline characteristics and the time course of changes in lung function in workers accidentally inhaling high concentrations of chlorine in a prospective study.

Methods-Baseline spirometry and methacholine challenge test were performed in a cohort of 278 workers at risk of accidental inhalation of chlorine. Workers in whom accidental inhalation led to intervention in a first aid unit were reassessed five to 25 days after the accident and serially thereafter when there where notable changes.

Results-During a four year follow up period, 13 workers were seen at the first aid unit after a symptomatic accidental inhalation. Three of them experienced notable functional changes: one worker experienced a $10 \%$ fall in forced expiratory volume in one second $\left(\mathrm{FEV}_{1}\right)$, and the other two had a notable fall in the concentration of methacholine that caused a $20 \%$ fall in $\mathrm{FEV}_{1}\left(\mathbf{P C}_{20}\right)$. Two workers were smokers and one had a personal history of atopy. Baseline assessment was within the normal range in these three workers. Recovery was complete three months after the accidental inhalation.

Conclusion-Transient but notable decreases in airway function or increases in bronchial responsiveness can occur after an accidental inhalation of high concentrations of chlorine in workers at risk. (Occup Environ Med 1998;55:356-359)
\end{abstract}

Keywords: bronchial diseases; irritants; occupational exposure; reactive airways dysfunction syndrome

Trois-Rivières, Canada

J-G Dufour

Correspondence to: Dr Denyse Gautrin, Department of Chest Medicine, Sacré-Coeur Hospital, 5400 West Gouin, Montreal, Canada H4J 1 C5. Tel: 0015143382222 , ext 2568; Fax: 001514338 3123. Email:

gautrind@crhsc.umontreal.ca

Accepted 27 November 1997

Reactive airways dysfunction syndrome (RADS) can be considered a type of occupational asthma, when it occurs at the workplace after an accidental inhalation exposure to high concentrations of an irritant agent. ${ }^{1}$ Several cases of RADS have been documented after massive chlorine exposure. ${ }^{2-5}$ In workers at risk of acute overexposure to chlorine, epidemiological studies from visits to first aid departments have provided some evidence of long term persistent symptoms, abnormalities in airway calibre, and bronchial hyperresponsiveness. ${ }^{4-6}$

The diagnosis of RADS is based on the history. Consequently, an assumption that a worker has been free of previous respiratory complaints may lead to a misdiagnosis. Moreover, functional assessment before the offending exposure is rarely available. The presence of bronchial hyperresponsiveness, which is mandatory for the diagnosis, is related to accidental massive exposure to an irritant agent. However, in some subjects, bronchial hyperresponsiveness might pre-exist as an underlying condition and might favour the onset of asthma-like symptoms when exposed to an offending agent. We previously performed a cross sectional study of respiratory symptoms, airway function, and bronchial responsiveness in a group of workers at risk of exposure to chlorine in a metal production plant. ${ }^{6}$ A slight but significant reduction in expiratory flow rates and an increase in bronchial responsiveness were documented in workers who had experienced repeated exposure to chlorine with mild symptoms compared with those who had reported asymptomatic exposure. A surveillance programme for workers who experienced accidental inhalation of chlorine was initiated in the same plant after the first survey. We describe here the time course of changes in lung function after accidental overexposure to chlorine in workers who were referred to the plant's first aid unit between 1992 and 1996 and for whom lung function variables had been previously measured.

Subjects and methods

EXPOSURE ASSESSMENT

The study took place in a metal production plant that started operations in 1989. Chlorine and $\mathrm{HCl}$ are used in the processes leading to purification of the metal. Workers can experience accidental inhalation exposure to chlorine in any area of the plant. Chlorine concentration is monitored on a continuous basis in the main areas with stationary sampling devices: if peak chlorine concentration reaches $1 \mathrm{ppm}$, workers are told to leave the upper floors of the 
Table 1 Baseline characteristics of the 13 workers who registered for first aid for an accidental chlorine inhalation over the four year study period, and the other workers

\begin{tabular}{|c|c|c|c|}
\hline & \multicolumn{2}{|c|}{ Acute chlorine inhalation } & \multirow[b]{2}{*}{$p$ Value } \\
\hline & Yes $(n=13)$ & No $(n=265)$ & \\
\hline \multicolumn{4}{|l|}{$\mathrm{n}(\%)$ : } \\
\hline \multicolumn{4}{|l|}{ Smoking habits: } \\
\hline Smokers & $4(30.7)$ & $66(24.9)$ & $0.84^{\star}$ \\
\hline Ex-smokers & $3(23)$ & $80(30)$ & \\
\hline Nonsmokers & $6(46.1)$ & $119(44.9)$ & \\
\hline \multicolumn{4}{|l|}{ Chronic symptoms: } \\
\hline Yes & $1(7.6)$ & $10(3.7)$ & 0.41 \\
\hline No & $12(92.3)$ & $255(96.2)$ & 0.21 \\
\hline Atopy & $6(46.1)$ & $76(28.6)$ & \\
\hline Yes & $7(53.8)$ & $189(71.3)$ & \\
\hline No & & & \\
\hline \multicolumn{4}{|c|}{ Previous report for first aid: } \\
\hline$\geqslant 1$ & $3(23)$ & $32(12)$ & 0.21 \\
\hline None & $10(76.9)$ & $233(87.9)$ & \\
\hline $\mathrm{FEV}^{1}<85 \%$ predicted & $4(30.7)$ & $21(7.9)$ & 0.02 \\
\hline FVC $<85 \%$ predicted & $2(15.3)$ & $12(4.5)$ & 0.16 \\
\hline $\mathrm{PC}_{20} \mathrm{mg} \cdot \mathrm{ml}^{-1}:$ & $2(15.4)$ & $25(9.4)$ & $0.41 \dagger$ \\
\hline$\leqslant 16$ & $1(15.4)$ & $13(4.9)$ & \\
\hline$>16-32$ & $10(69.2)$ & $227(85.6)$ & \\
\hline$>32$ & & & \\
\hline \multicolumn{4}{|l|}{ Mean (SD) \% predicted: } \\
\hline $\mathrm{FEV}_{1}$ & $90.2(9.4)$ & $99.6(12)$ & 0.006 \\
\hline FVC & $95.1(8.5)$ & $101.5(10.6)$ & 0.03 \\
\hline $\mathrm{FEV}_{1} / \mathrm{FVC}$ & $94.4(4.8)$ & $97.9(5.8)$ & 0.03 \\
\hline
\end{tabular}

${ }^{\star} \chi^{2}$ analysis from a 2 row (non-smokers $v$ others) 2 column analysis.

$+\chi^{2}$ analysis from a 2 row $\left(\mathrm{PC}_{20} \leqslant 16 v \mathrm{PC}_{20}>16\right) 2$ column analysis.

area, if chlorine peak concentration reaches 3 ppm, workers are requested to leave the contaminated area immediately. The portable apparatus currently in use, the Metrosonic PM7700, does not assess maximal peak chlorine concentrations. This instrument reads chlorine concentrations progressively over a three minute recording period. That is, the instrument's reading is accurate only when continuous exposure for three minutes has occurred. However, workers-especially those not wearing respiratory protective equipment - can sense the presence of chlorine gas and consequently leave the contaminated area before that time has elapsed. After two minutes the instrument's electrochemical cells can read about $90 \%$ of the actual concentration of chlorine gas.

BASELINE ASSESSMENT OF SYMPTOMS AND LUNG FUNCTION

Details on the initial assessment of this cohort of workers are provided elsewhere. ${ }^{6}$ Briefly, data were collected by a trained nurse and two medical technologists at the workplace during three months in the Autumn of 1992. A French adapted version of the International Union against Tuberculosis and Lung Diseases questionnaire $^{8}$ was used to assess the presence of chronic respiratory symptoms, smoking, and history of atopy (defined by at least one positive answer to "Have you ever suffered from hay fever", or "eczema", or "urticaria").

Spirometry was performed according to the American Thoracic Society standards. ${ }^{9}$ Reference values for forced expiratory volume in one second $\left(\mathrm{FEV}_{1}\right)$ and forced vital capacity (FVC) were obtained from Knudson et al. ${ }^{10}$ Bronchial responsiveness was assessed with methacholine to a maximum of $32 \mathrm{mg} \cdot \mathrm{ml}^{-1}$ with a Wright's nebuliser (output, $0.14 \mathrm{ml} \cdot \mathrm{min}^{-1}$ ) at tidal volume breathing for two minutes. ${ }^{11}$ The concentration of methacholine causing a $20 \%$ fall in $\mathrm{FEV}_{1}\left(\mathrm{PC}_{20}\right)$ was derived from individual dose-response curves drawn on a semilogarithmic scale. A $\mathrm{PC}_{20} \leqslant 16 \mathrm{mg} \cdot \mathrm{ml}^{-1}$ implied bronchial hyperresponsiveness. All workers employed after the end of the cross sectional study ( $\mathrm{n}=39$ ) were assessed in the same way when starting their jobs and were included in this study.

REPORTING OF ACCIDENTS AND MANAGEMENT OF WORKERS

The medical unit at the workplace is equipped to provide round the clock first aid care as needed for accidental exposure to high concentrations of chlorine, or occasionally, other irritant agents $\left(\mathrm{HCl}\right.$, ammonia, $\mathrm{SF}_{6}, \mathrm{H}_{2} \mathrm{~S}$, or $\left.\mathrm{S}\right)$. From the time the plant started its operations to the 1992 baseline assessment, 42 workers reported at least one accidental inhalation to the first aid unit. After the baseline assessment the following procedures were set up: any worker who was accidentally exposed to high concentrations of chlorine or another irritant gas, and who immediately experienced severe respiratory symptoms, would report this accidental inhalation episode to the first aid unit. Also, workers present on a site where a peak overexposure was measured were given instructions to report to the first aid station even if they would not have done so on their own. The nurse or, during the night, another trained person would assess respiratory complaints, give bronchodilator medication, and monitor the worker as needed until recovery from the acute symptoms. Furthermore, both spirometry and a methacholine bronchial challenge test were performed within three weeks of the accidental inhalation. If notable changes from baseline occurred, monthly reassessment was done until recovery.

Table 2 Surveillance of accidental chlorine inhalation 1992-6: results of repeated functional assessments and methacholine challenge tests

\begin{tabular}{|c|c|c|c|c|c|c|c|c|c|c|c|c|c|}
\hline \multirow[b]{2}{*}{ Subject } & \multirow{2}{*}{$\begin{array}{l}\text { Age } \\
(y)\end{array}$} & \multirow{2}{*}{$\begin{array}{l}\text { Smoker } \\
\text { status }\end{array}$} & \multirow{2}{*}{$\begin{array}{l}\text { Previous visits to } \\
\text { first aid }(n)\end{array}$} & \multirow{2}{*}{$\begin{array}{l}\text { Duration of acute } \\
\text { symptoms }(h)\end{array}$} & \multicolumn{3}{|c|}{$F E V_{1}, \%$ predicted } & \multicolumn{3}{|c|}{$F V C, \%$ predicted } & \multicolumn{3}{|c|}{$P C_{20}, m g . m l^{-1}$} \\
\hline & & & & & Baseline & Accident & Follow up & Baseline & Accident & Follow up & Baseline & Accident & Follow-up \\
\hline 1 & 31 & Yes & 0 & 12 & 90.4 & 90.2 & 89.4 & 94.9 & 94.7 & 93.9 & $>32$ & 11.5 & $>32$ \\
\hline 2 & 36 & Yes & 2 & 1 & 94.1 & 87.3 & 91.7 & 104.3 & 100.5 & 104.1 & $>32$ & 19.5 & $>32$ \\
\hline 3 & 24 & No & 0 & 72 & 102.5 & 97.1 & 100.5 & 101.6 & 97.7 & 98.8 & 17 & 5.2 & 13.2 \\
\hline 4 & 36 & No & 0 & 1 & 102.0 & 102.2 & & 99.6 & 98.3 & & $>32$ & $>32$ & \\
\hline 5 & 28 & No & 3 & 5 & 85.7 & 85.4 & 85.1 & 91.7 & 91.7 & 87.4 & 4 & 24 & 21 \\
\hline 6 & 28 & No & 0 & 8 & 94.6 & 100.6 & & 99.1 & 101.6 & & $>32$ & $>32$ & \\
\hline 7 & 37 & Yes & 0 & 5 & 76.0 & 74.6 & & 90.3 & 86.3 & & $>32$ & $>32$ & \\
\hline 8 & 20 & No & 0 & 8 & 84.3 & 79.1 & & 83.5 & 79.0 & & $>32$ & $>32$ & \\
\hline 9 & 32 & No & 1 & 1 & 97.4 & 101.4 & & 106.1 & 106.1 & & $>32$ & $>32$ & \\
\hline 10 & 30 & Yes & 0 & 1 & 81.9 & 88.0 & & 85.9 & 91.4 & & $>32$ & 18 & \\
\hline 11 & 30 & No & 0 & 1 & 83.1 & 87.3 & & 83.5 & 89.1 & & 16 & $>32$ & \\
\hline 12 & 34 & No & 0 & 24 & 86.4 & 82.5 & & 86.3 & 82.6 & & $>32$ & $>32$ & \\
\hline 13 & 35 & No & 0 & 48 & 102.9 & 104.8 & & 107.5 & 112.5 & & $>32$ & $>32$ & \\
\hline
\end{tabular}


ANALYSIS

Definition of a notable functional change included: (a) a decline in $\mathrm{FEV}_{1} \geqslant 10 \%$ (absolute values) from baseline $\left(\left(\mathrm{FEV}_{1}\right.\right.$ before the accident- $\mathrm{FEV}_{1}$ after the accident) $/ \mathrm{FEV}_{1}$ before the accident), (b) a $\mathrm{PC}_{20} \leqslant 16 \mathrm{mg} / \mathrm{ml}$ at follow up in subjects with normal baseline bronchial responsiveness, (c) a 3.2-fold decrease in $\mathrm{PC}_{20}$ (the $95 \%$ confidence interval (95\% CI) for reproducibility) if baseline $\mathrm{PC}_{20}$ was $<16 \mathrm{mg} / \mathrm{ml}^{12}{ }^{13}$ Unpaired Student's $t$ tests, $\chi^{2}$ analysis, and Fisher's exact tests were used, and a $\mathrm{p}$ value $<0.05$ was considered to be significant. The study protocol was approved by the Hôpital du Sacré-Coeur ethics committee and written consent was obtained from all participants.

\section{Results}

From 1 January 1993 to 1 November 1996, 13 workers were seen at the first aid unit for accidental inhalation of high concentrations of chlorine. All were men, and the mean (range) age was 31 (20-37) years. Table 1 shows the characteristics at the initial assessment for these 13 subjects, as well as for the remaining workers who were not seen at the first aid unit during that period. No significant differences were found between the two groups for smoking habits, frequency of either reported chronic symptoms or history of personal atopy, number of previous accidents reported to the first aid unit, or distribution into categories of abnormal bronchial responsiveness; the mean $\mathrm{FEV}_{1}$, $\mathrm{FVC}$, and $\mathrm{FEV}_{1} / \mathrm{FVC}$ ratio were significantly lower in the 13 workers seen at the first aid unit.

All 13 subjects reported an immediate onset of symptoms after accidental inhalation exposure. The main acute symptoms were throat irritation $(n=7)$, cough $(n=10)$, and shortness of breath $(n=10)$. Mean (range) duration of acute symptoms was brief (14.4 (1-72) hours). Immediate treatment consisted of inhaled bronchodilators in 10 cases. No antiinflammatory drugs were given.

Functional assessment and a methacholine challenge test were performed five to 25 days (mean 11.5 days) after the offending exposure (table 2). Two subjects showed a notable fall in $\mathrm{PC}_{20}$, as defined above and one subject, a $9.5 \%$ fall in $\mathrm{FEV}_{1}$ (4.2 v 3.8 litres). These three subjects had a baseline assessment of airway calibre and bronchial responsiveness within the normal range. Two of these subjects were smokers and one had a history of personal atopy. Subjects 1 and 3 showed bronchial hyperresponsiveness after the acute inhalation. However, $\mathrm{PC}_{20}$ returned to the baseline after three to four months of follow up. In subject 2, a transient decrease in $\mathrm{FEV}_{1}$, from $94.1 \%$ to $87.3 \%$ predicted, was found with recovery thereafter. Among the remaining 10 subjects, subject 5 had reported three previous accidental inhalation episodes to first aid, had a history of atopy, and had shown bronchial hyperresponsiveness at the baseline assessment. After the accidental inhalation, $\mathrm{PC}_{20}$ was above 16 $\mathrm{mg} \cdot \mathrm{ml}^{-1}$.

\section{Discussion}

This study shows that a transient but notable decrease in airway function or increase in bronchial responsiveness can occur after an accidental inhalation of high concentrations of chlorine in workers at risk. Three subjects among the 13 who consulted the first aid unit after an accidental inhalation experienced such changes. As no anti-inflammatory treatment was given, these changes might reflect the natural history of bronchial injury after accidental inhalation to high concentrations of an irritant agent. For the first time to our knowledge, data from baseline assessment before the occurrence of an accidental inhalation episode were available. From these data, it is evident that baseline characteristics of workers who experienced an accidental inhalation episode were not significantly different from those of other workers, except for $\mathrm{FEV}_{1}, \mathrm{FVC}$, and $\mathrm{FEV}_{1} / \mathrm{FVC}$, which were lower. Whether subjects with lower spirometric values are more prone to experience symptoms after exposure remains to be elucidated. The three subjects who showed a notable change in airway function and responsiveness had normal values before the accidental exposure. On the other hand, a fourth subject with normal PC $_{20}$ values after the accidental inhalation had increased bronchial responsiveness when first assessed. This subject reported a history of atopy, but had also experienced three previous episodes of accidental inhalation. These factors may account for the initial abnormal findings.

Our findings suggest that after an accidental inhalation exposure to high concentrations of chlorine, severe respiratory symptoms are no more likely to occur in subjects with preexisting bronchial hyperresponsiveness than in other workers at risk. D'Alessandro et al studied airway response to chlorine at a concentration of $1 \mathrm{ppm}$, which is the recommended occupational 15 minute ceiling short term exposure limit, for 60 minutes in five subjects with and five subjects without airway hyperresponsiveness. ${ }^{14}$ Two subjects in the so called bronchial hyperresponsiveness group experienced symptoms after exposure. Although a notable fall in $\mathrm{FEV}_{1}$ occurred in the groups both with and without bronchial hyperresponsiveness immediately after exposure, the fall was greater in the bronchial hyperresponsiveness group. This suggests that a susceptible subpopulation may respond acutely to the offending agent with a greater decrement in pulmonary function. Our results are not contradictory, but show that surveillance of workers at risk of chlorine exposure cannot be restricted to those subjects with pre-existing airway hyperresponsiveness.

It is difficult to compare the time course of abnormalities in function and airway responsiveness after massive exposure to an offending agent with other studies because of the lack of baseline assessment in previous reports. Blanc et al studied 10 subjects recovering from a single toxic inhalation exposure: none had abnormal airflow when assessed within two weeks of exposure, but eight showed airway hyperresponsiveness. ${ }^{15}$ By three months, airway 
hyperresponsiveness had reversed in only one subject. Bhérer et al studied 51 construction workers at risk of developing RADS due to repeated exposure to chlorine gas during renovations to a pulpmill: functional assessment at 18-24 months after exposure showed that 16 $(31 \%)$ had abnormal airflow, and $29(56 \%)$ had airway hyperresponsiveness. ${ }^{16}$ When further assessed by Malo et al 30 to 36 months after exposure, 18 of these 29 subjects showed no notable change in $\mathrm{FEV}_{1}$, but six of them had considerable improvement in $\mathrm{PC}_{20}$ results. ${ }^{17}$ These findings, like those of the present study, suggest that less pronounced bronchial alterations induced by exposure to chlorine may be reversible.

Few workers, specifically $4.6 \%$ (13/278), visited the first aid unit after accidental inhalation episodes during this four year study period. It seems unlikely that workers experiencing severe symptoms after acute exposure to chlorine would not contact first aid, because all workers had been advised in advance to pay a visit to the first aid department if such an event occurred. Salisbury et al studied a group of 316 pulpmill workers, and reviewed first aid reports of incidents of acute chlorine inhalation over an eight year period. ${ }^{18}$ There was a greater decline in $\mathrm{FEV}_{1} / \mathrm{FVC}$ ratio and midmaximal flow rate in the exposed group than in the nonexposed group. The authors suggested that first aid reports may be reliable predictors of abnormalities of lung function. In a study of 281 construction workers repeatedly exposed to chlorine, Courteau et al found that first aid referral was significantly associated with the presence of immediate respiratory symptoms. ${ }^{19}$ However, the proportion of workers who reported accidental inhalation but had never gone to the first aid unit was high (153/257). This could be attributed to the fact that these construction workers were not familiar with the occupational hazard of chlorine or the first aid facilities.

In summary, this is the first report that shows deterioration in airway function of subjects who experienced an accidental inhalation episode and in whom pre-exposure function measures were available. Changes were transient. Preexisting bronchial hyperresponsiveness did not seem to be a predisposing factor, although the limited number of workers who experienced events and presented at the first aid unit precludes drawing any firm conclusions.
We thank the employer and workers whose willing cooperation made the study possible, the nurse, D Girard who administered the questionnaires, the medical technologists, L Cyr Dufour and $\mathrm{H}$ O'Grady who administered the respiratory function tests, and $\mathrm{L}$ Schubert who reviewed the manuscript. This work was supported by the Fonds de recherche en santé du Québec (FRSQ, program 16.1), the Centre québécois d'excellence en santé respiratoire, and the Quebec Lung Association. DG is a research scholar with the FRSQ.

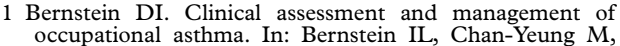
occupational asthma. In: Bernstein IL, Chan-Yeung M,
Malo JL, et al, eds. Asthma in the workplace. New York: Maro JL, et al, eds. Asthma

2 Boulet LP. Increases in airway responsiveness following acute exposure to respiratory irritants. Reactive airway dysfunction syndrome or occupational asthma? Chest 1988; 94:476-81.

3 Tarlo S, Broder I. Irritant-induced occupational asthma. Chest 1989;96:297-300.

4 Donnelly SC, Fitzgerald MX. Reactive airways dysfunction syndrome (RADS) due to chlorine gas exposure. Irish Med f 1990;159:275-7.

5 Moore B, Sherman M. Chronic reactive airway disease following acute chlorine gas exposure in an atopic patient. Chest 1991;100:855-6.

6 Gautrin D, Leroyer C, L'Archevêque J, et al. Cross sectional assessment of workers with repeated exposure to chlorine over a three year period. Eur Respir f 1996;8:2046-54.

7 Kennedy S. Acquired airway hyperresponsiveness from non-immunogenic irritant exposure. Occup Med 1992;7: non-imm $287-300$.

8 Burney P, Chinn S, Britton J, et al. What symptoms predict the bronchial response to histamine? Evaluation in a community survey of the bronchial symptoms questionnaire 1984) of The International Union Against Tuberculosis and Lung Disease. Int $\mathcal{F}$ Epidemiol 1989;18:165-73.

9 American Thoracic Society. Standardization of spirometry: 1987 Update. Am Rev Respir Dis 1987;136:1285-307.

10 Knudson RJ, Slatin RC, Lebowitz MD, et al. Changes in the normal maximal expiratory flow-volume curve with growth and aging. Am Rev Respir Dis 1983;127:725-34.

11 Cockcroft DW, Killian DN, Mellon JJ, et al. Bronchial reactivity to inhaled histamine: a method and clinical survey. Clin Allergy 1977;7:235-43.

12 Malo JL, Pineau L, Cartier A, et al. Reference values of the provocative concentrations of methacholine that cause $6 \%$ provocative concentrations of methacholine that cause $6 \%$
and $20 \%$ changes in forced expiratory volume in one second in a normal population. Am Rev Respir Dis second in a nor

13 Dehaut P, Rachiele A, Martin RR, et al. Histamine dose-response curves in asthma: reproducibility and sensitivity of different indices to assess response. Thorax 1983;38:516-22

14 D'Alessandro A, Kushner W, Wong H, et al. Exaggerated response to chlorine inhalation among persons with non-specific airway hyperreactivity. Chest 1996;109:331-7.

15 Blanc PD, Galbo M, Hiatt P, et al. Symptoms, lung function, and airway responsiveness following irritant inhalation. Chest 1993;103:1699-705.

16 Bherer L, Cushman R, Courteau J, et al. Survey of construction workers repeatedly exposed to chlorine over a three to six month period in a pulpmill: II follow up of affected workers by questionnaire, spirometry, and assesseaffected workers by questionnaire, spirometry, and assessement of bronchial responsiveness 18 to 24 months

17 Malo JL, Cartier A, Boulet LP, et al. Bronchial hyperrsponsiveness can improve while spirometry plateaus two to three years after repeated exposure to chlorine causing respiratory symptoms. Am $\mathcal{F}$ Respir Crit Care Med 1994;150: 1142-5.

18 Salisbury DA, Enarson DA, Chan-Yeung M, et al. First aid reports of acute chlorine gassing among pulpmill workers as predictors of lung health consequences. Am $\mathcal{F}$ Ind $\mathrm{Med}$ 1991;20:71-81.

19 Courteau JP, Cushman R, Bouchard F, et al. Survey of construction workers repeatedly exposed to chlorine over a three to six month period in a pulpmill: I exposure and symptomatology. Occup Environ Med 1994;51:225-8. 